\title{
The mental impression and the doctrine of reincarnation leading to the characteristic hereditary transmissions through the consciousness model
}

\author{
Dhananjay Pal \\ Email address: \\ dhananjay.pal123@gmail.com,paldhananjay46@yahoo.com
}

Pharmacy College, Bengal School of Technology, Sugandha-Delhi Road, Chuchura, Dist.-Hooghly, West Bengal, INDIA, PIN-712 102

\section{To cite this article:}

Dhananjay Pal. The Mental Impression and the Doctrine of Reincarnation Leading to the Characteristic Hereditary Transmissions through the Consciousness Model. American Journal of Modern Physicy. Vol. 2, No. 6, 2013, pp. 392-401.

doi: 10.11648/j.ajmp.20130206.27

\begin{abstract}
A single field emerged at the origin of the universe, already containing within itself the blueprint of the physical universe. The primordial single field triggered the onset of the universe. Most physicists believe that a single super-force dominated the first instants of creation. Scientists have arrived at a simple but decisive conclusion that consciousness is very much a part of the universe, like other objects. Our consciousness model involving thought-carrying particle (TCP), thought retaining particle (TRP) and thought force $\left(\mathrm{T}_{\mathrm{F}}\right)$ signifies the existence of universal consciousness that exists along with the universe. This universal consciousness is a functional state of the universal mind (UM). This UM is evolved at the Big Bang from void. The UM is constituted by these TCP and TRP in the inherent presence of thought force $\left(\mathrm{T}_{\mathrm{F}}\right)$. Thought force $\left(\mathrm{T}_{\mathrm{F}}\right)$ is an expression of universal consciousness. The Thought force $\left(\mathrm{T}_{\mathrm{F}}\right)$ being the primordial quantum field functions as the original super-force. $\mathrm{T}_{\mathrm{F}}$ being the original super-force functions as the origin of all the fundamental fields. TCP is the carrier of thought force $\left(\mathrm{T}_{\mathrm{F}}\right)$ that, in turn, appears to be the origin of all the fields. The quantized energy $\left(\varepsilon_{T}\right)$ of TCP is responsible to cause the universal consciousness as well as the cosmic microwave background radiation temperature. The individual consciousness owes its origin to the universal consciousness created by the same $\varepsilon_{T}$. The same $\varepsilon_{T}$ is the energy responsible for generating thought force $\left(\mathrm{T}_{\mathrm{F}}\right) . \mathrm{T}_{\mathrm{F}}$ being an expression of the universal consciousness is applicable to any inanimate object as well as to any biological system (having thinking ability). The $\mathrm{T}_{\mathrm{F}}$ exerts its functions both in vitro and in vivo. These TCP, TRP and the thought force $\left(\mathrm{T}_{\mathrm{F}}\right)$ in vitro and thought force $\left(\mathrm{T}_{\mathrm{F}}\right)$ in vivo can address the meaning of mental impression and the doctrine of reincarnation leading to the characteristic hereditary transmissions.
\end{abstract}

Keywords: Void, Cosmic Microwave Background Radiation (CMBR), Universal Mind (UM), Thought Force ( $\mathrm{T}_{\mathrm{F}}$ ), Though-Carrying Particle (TCP), Thought Retaining Particle (TRP), Quantized Energy $\left(\varepsilon_{T}\right)$ of TCP

\section{Introduction}

In Eastern philosophical traditions, consciousness is intrinsic to the universe, whereas in most Western views, consciousness is extrinsic, emerging from complex computation. How can these views be reconciled?

It is most relevant and important to indicate the names of various eminent physicists like Erwin Schrödinger, Eugene Wigner, Brian Josephson, John Wheeler, Roger Penrose, Henry P Stapp, Freeman J. Dyson, Paul Davies, David Bohm, Basil Hiley, Fritjof Capra, Fred Alan Wolf and Amit Goswami who have addressed the inclusion of consciousness in their work. Consciousness is to be taken into account.

1.1. In contrast to the usual linear sequence of matter, body, life, brain, mind, consciousness, here the proposed cyclic sequence is first universal consciousness (a functional state of the universal mind), and then matter, body, life, brain, and regeneration of mind and consciousness. The evolution of life with mind and consciousness is possible purely due to the inherent existence of universal consciousness which exists along with the universe. The human nervous system is evolved to provide an appropriate material structure to individualize the universal consciousness, a characteristic of reality, pervading all manifestations. 
Consciousness model of Pal et al [1-3] involving TCP, TRP and thought force $\left(\mathrm{T}_{\mathrm{F}}\right)$ signifies the existence of universal consciousness that exists along with the universe. Pal et al [3] showed that this universal consciousness is a functional state of Universal Mind (UM). Pal et al [3] explained that the UM is evolved at the Big Bang from the eternal Void. This Void, in turn, is the source of infinite energy. And this UM is a finer matter. The individual mind being a constituent of the UM is also a finer matter. The constituents of the UM and individual mind are the same. The ultimate constituents of matter and mind are the same as both mind and matter are aspects of one fundamental reality, which is called UM. The brain is the mediating link or interface between the individual mind and body.

Pal et al [3] explained that the constituents of the UM are the ultimate constituents of matter itself as everything in this universe is a manifestation of this UM. Pal et al [3] expressed that the UM is constituted by these TCP and TRP in the inherent presence of thought force $\left(\mathrm{T}_{\mathrm{F}}\right)$. Pal et al $[1,3]$ further explained that the ultimate constituents of matter and mind are these TCP and TRP in the inherent presence of thought force $\left(\mathrm{T}_{\mathrm{F}}\right)$ in vitro and thought force $\left(\mathrm{T}_{\mathrm{F}}\right)$ in vivo.

Physicists determined that underlying quantum fields give birth to elementary particles. Bhaumik [4] mentioned that Frank Wilczek pointed out, "In quantum field theory, the primary elements of reality are not individual particles, but underlying fields. Thus, for example, all electrons are but excitations of an underlying field, naturally called electric field". The same holds true for all the fundamental particles of which matter is made.

The existence of matter depends on the existence of force and vice versa. TCP cannot exist without TRP and vice versa. Many physicists believe that unifying all the forces, including gravity, into a single theory would require a phenomenon called super-symmetry. With supersymmetry, every fermion would have a boson twin, and vice-versa. The thought force $\left(\mathrm{T}_{\mathrm{F}}\right)$ is carried by the TCP in the presence of its super-symmetrical partner TRP. TCP that behaves like boson should accompany its supersymmetrical partner TRP that functions like fermion in the generalized simpler way. It is to be noted that these TCP and TRP function like wavicle: wave-particle duality.

\section{Thought Force}

Pal et al [1, 3] and Pal [5] explained the existence of thought force $\left(\mathrm{T}_{\mathrm{F}}\right)$. Thought force $\left(\mathrm{T}_{\mathrm{F}}\right)$, an expression of the universal consciousness, is the primordial quantum field that, in turn, functions as the primary unified field. This $T_{F}$ being an expression of the universal consciousness is applicable to any inanimate object as well as to any biological system (having thinking ability). Thus the $T_{F}$ being an expression of the universal consciousness exerts its functions both in vitro and in vivo.

Physicists determined that underlying quantum fields give birth to elementary particles. Pal [5] expressed that the thought force $\left(\mathrm{T}_{\mathrm{F}}\right)$ is the primordial quantum field. Thought force $\left(\mathrm{T}_{\mathrm{F}}\right)$ being the primordial quantum field functions as the primary unified field. Thought force $\left(\mathrm{T}_{\mathrm{F}}\right)$ being the primordial quantum field gives birth to TRP that appears to be the origin of all the matter particles. TCP is the carrier of thought force $\left(\mathrm{T}_{\mathrm{F}}\right)$ that, in turn, appears to be the origin of all the fields. TCP thus appears to be the origin of all the field particles.

In a purpose to involve both the non-living and living systems of the world, Pal [5] has shown the existences of these TCP, TRP and thought force $\left(\mathrm{T}_{\mathrm{F}}\right)$ in vitro and thought force $\left(\mathrm{T}_{\mathrm{F}}\right)$ in vivo. Anyone can call this TCP by any other name, but as the highly developed living system will have to be evolved in the universe in the long run and as the thought of highly developed living system appears to be a kind of force to be called the thought force $\left(\mathrm{T}_{\mathrm{F}}\right)$ in vivo, we considered it is wise to call it as TCP. Further, as the universe exists along with the universal consciousness that, in turn, is created by the quantized energy $\left(\varepsilon_{T}\right)$ of TCP, we had to use the term TCP.

Pal (5) expressed that the non-living system of the world is governed by the thought force $\left(\mathrm{T}_{\mathrm{F}}\right)$ in vitro and this Thought force $\left(\mathrm{T}_{\mathrm{F}}\right)$ in vitro gives rise to $\mathrm{T}_{\mathrm{F}}$ (micro), $\mathrm{SNF}$, EMF, WNF, GF and $\mathrm{T}_{\mathrm{F}}$ (macro) where $\mathrm{T}_{\mathrm{F}}$ (micro) $=$ Thought force in microcosm, SNF = Strong nuclear force, $\mathrm{EMF}=$ Electromagnetic force, $\mathrm{WNF}=$ Weak nuclear force, $\mathrm{GF}=$ Gravitational force and $\mathrm{T}_{\mathrm{F}}$ (macro) $=$ Thought force in macrocosm. It is to be noted here that $\mathrm{T}_{\mathrm{F}}$ (micro) is a stronger force than the SNF and $\mathrm{T}_{\mathrm{F}}$ (macro) is a weaker force even than the GF.

Pal (5) also expressed that the living system of the world is governed by the thought force $\left(\mathrm{T}_{\mathrm{F}}\right)$ in vivo and this Thought force $\left(\mathrm{T}_{\mathrm{F}}\right)$ in vivo is a type of force that represents the biological 'thought' which is the action of mind. This 'thought' being a type of force controls the 'thought processes' involving the firing of neurons through the quantum mechanical activities of these TCP and TRP in the presence of consciousness. Consciousness in living organisms is a process which involves the quantum mechanical activities of these TCP and TRP, the ultimate constituents of any matter as well as any mind in the inherent presence of thought force $\left(\mathrm{T}_{\mathrm{F}}\right)$ in vitro and the thought force $\left(\mathrm{T}_{\mathrm{F}}\right)$ in vivo as indicated by Pal et al [3]. This consciousness, in turn, is the quantized energy $\left(\varepsilon_{T}\right)$ of TCP. The thought force $\left(\mathrm{T}_{\mathrm{F}}\right)$ in vivo is demonstrated in numerous experiments in which thought has an effect on a physical process (often known as mind over matter). This biological 'thought' is a type of force that can cause movement. Controlling movement through thought alone is observed in several experiments conducted by many scientists as indicated by Pal (5). These experiments thus signify the existence of thought force $\left(\mathrm{T}_{\mathrm{F}}\right)$ in vivo.

Pal [5] explained the existence of $\mathrm{T}_{\mathrm{F}}$ (micro) (= Thought force in microcosm). This $\mathrm{T}_{\mathrm{F}}$ (micro) is the strongest interaction (a new class of 'extra strong' interaction). It is stronger than SNF (Strong Nuclear Force).

Pal [5] has also shown the existence of $\mathrm{T}_{\mathrm{F}}$ (macro) (= Thought force in macrocosm). It is the "weakest force" 
which is much weaker even than the gravity.

2.1. Pal et al [3] developed three different equations $\varepsilon_{T}$ in one of the three equations is shown below: expressing the quantized energy ( $\varepsilon_{T}$ ) of TCP. The value of

$$
\varepsilon_{T}=4.384 \times 10^{-16} \mathrm{erg} \equiv 2.73 \times 10^{-4} \mathrm{eV} \equiv 2.73 \mathrm{~K} \cong C M B R \text { temperature } \equiv 2.725 \mathrm{~K} \text {. }
$$

This conversion of erg $\equiv \mathrm{eV} \equiv \mathrm{K}$ is given by Weisskopf [6] as follows:

$$
1 \mathrm{erg} \cong 0.6241807 \times 10^{12} \mathrm{eV} \text { and } 10^{-4} \mathrm{eV} \cong 1 \mathrm{~K}
$$

2.2. Pal et al [3] expressed that the CMBR temperature is due to $\varepsilon_{T}$, the quantized energy of TCP where

$$
\varepsilon_{T}=4.384 \times 10^{-16} \mathrm{erg} \equiv 2.73 \times 10^{-4} \mathrm{eV} \equiv 2.73 \mathrm{~K} \cong C M B R \text { temperature } \equiv 2.725 \mathrm{~K} .
$$

As per Pal et al [3], it is interesting to note that all of the three different equations ultimately give rise to the same result that is equivalent to the CMBR temperature. A sort of relationship is thus observed between the $\varepsilon_{T}$ and the CMBR temperature. This coincidence is thus signifying a probable role of TCP on the maintenance of CMBR temperature. Further, this coincidence is also signifying the existence of these TCP in the presence of TRP. TCP cannot exist without TRP and vice versa. The presence of TCP, TRP and Thought force $\left(\mathrm{T}_{\mathrm{F}}\right)$ in the universe is thus indicated and expressed mathematically. At present we are unable to explain when and how these TCP and TRP decoupled from the primordial cosmic soup.

Pal et al $[1,3]$ showed that the quantized energy $\left(\varepsilon_{T}\right)$ of TCP is responsible to cause the universal consciousness as well as the cosmic microwave background radiation temperature. The individual consciousness owes its origin to the universal consciousness created by the same $\varepsilon_{T}$. Ultimately this $\mathcal{E}_{T}$ represents universal consciousness. The existence of CMBR temperature indicates the existence of the TCP in the presence of TRP. The existence of TCP ensures the existence of the thought force $\left(\mathrm{T}_{\mathrm{F}}\right)$. Further, this $\mathrm{T}_{\mathrm{F}}$ being an expression of the quantized energy $\left(\boldsymbol{\varepsilon}_{T}\right)$ of TCP exerts its functions both in vitro and in vivo.

\section{What is Life?}

Life is a state of flux that is being maintained by a typical form of energy which is nothing but the consciousness itself. Pal et al [3] and Pal [7] showed that the quantized energy $\left(\varepsilon_{T}\right)$ of TCP is responsible to cause the universal consciousness as well as the cosmic microwave background radiation temperature. The individual consciousness owes its origin to the universal consciousness created by the same $\varepsilon_{T}$. Pal et al $[1,3]$ and Pal [7] explained that life may be defined as a state of functional manifestation of consciousness that, in turn, is the quantized energy ( $\varepsilon_{T}$ ) of TCP. This $\mathcal{E}_{T}$ represents universal consciousness.

$$
\text { Thus, Life }=\mathrm{f}(\text { Consciousness })=\mathrm{f}\left(\boldsymbol{E}_{T}\right)
$$

Where $\varepsilon_{T}=$ quantized energy of the TCP $=4.384 \times 10^{-16} \mathrm{erg}$.

$$
\varepsilon_{T}=h v_{T}=h c / \lambda_{T}=4.384 \times 10^{-16} \mathrm{erg}
$$

Where

$\varepsilon_{T}=$ quantized energy of the TCP $=4.384 \times 10^{-16} \mathrm{erg}$,

$\boldsymbol{V}_{T}=$ frequency of the TCP $=\boldsymbol{\varepsilon}_{T} / h=66.12 \times 10^{9} \mathrm{~Hz} .=66.12 \mathrm{GHz}$,

$\mathrm{h}=$ Planck's quantum constant $=6.63 \times 10^{-27} \mathrm{erg}$. sec,

$\mathrm{c}=$ free-space velocity of light $=3 \times 10^{10} \mathrm{~cm} / \mathrm{sec}$,

$\lambda_{T}=$ wave-length of the $\mathrm{TCP}=0.4537 \mathrm{~cm}$.

\subsection{What is Consciousness?}

Psychologists, neuroscientists, philosophers, and other professionals continue to engage in an ongoing debate as to what consciousness means. In reality, we may never know. Is it a product of the biological and classical physical interactions of the human brain; or is it something more fundamental, perhaps electromagnetic, or the result of quantum physics principles that we don't yet fully understand? Could it be something even more profound than that -- something beyond the scope of science and physics, any kind of physics, for us to understand?

According to the ancient Vedanta, consciousness is not an emergent property of matter that comes into existence only through the functioning of the human nervous system. Instead, consciousness is a characteristic of reality, pervading all manifestations. This unbounded field of nature's universal consciousness is not limited to an individual consciousness. From this viewpoint, the role of the human nervous system is to provide an appropriate material structure to individualize the universal consciousness. It appears that inanimate matter itself cannot generate consciousness without the inherent existence of universal consciousness.

Pal et al [2] explained, "Consciousness is the realization of existence, and there are as many states of consciousness as there are states of existence. Every living being has a consciousness of its own depending on complexity of the 
brain and the activity of the viable numbers of TCP in the presence of TRP; and the state of its consciousness changes every moment of time. Consciousness is the perception of the relation it bears to things and as this relation changes, consciousness changes its character. Consciousness itself does not change; it only moves up and down on the 'scale of the realization' of existence through the 'sub-conscious', 'conscious' and 'super-conscious' states". There is another term called unconscious state. The most usual unconscious state is sleep. A deeper form of unconsciousness is called a coma.

\subsection{Possible Relation of Consciousness with Mind: Possible Relation of Animate with Inanimate through Consciousness}

Modern scientists have not even been able to arrive at a consensus on what should be a definition of the totality of consciousness. The brain is intricately linked to the process of consciousness and consciousness is thought to be a phenomenon of the mind.

It appears that

$$
\text { Consciousness }=\mathrm{f}(\operatorname{mind})
$$

Consciousness is the functional state of mind. Presence of consciousness signifies the presence of mind and vice versa.

It is apparent that

$$
\text { Animate } \neq \text { Inanimate }
$$

Three critical factors which distinguish life from nonliving are consciousness, metabolism and reproduction. (4):

In a gross presentation, we can express from the equation

$$
\text { Animate }- \text { Consciousness }=\text { Inanimate }
$$

Scientists would have to define and characterize consciousness properly. We should have the proper knowledge about the exact characteristics of consciousness in order to address many present day scientific enigmas.

\subsection{Consciousness may be Defined as the 'Self- Organized' Capability of any Living being to Activate TCP and TRP}

Pal et al [3] expressed that consciousness may be defined as the 'self-organized' capability of any living being to activate TCP and TRP, the ultimate constituents of mind and matter and to exert its functions. What can generate, maintain and activate TCP and TRP is called animate having 'active consciousness' and what cannot is called inanimate, i.e., devoid of active consciousness. As anything inanimate does neither have the power to activate the TCP and TRP nor have the capability to catalyze the activity of TCP and TRP, so it cannot generate consciousness. On the contrary, anything animate has the 'self-organized' power to generate, activate and catalyze the activity of TCP and
TRP in order to generate and maintain consciousness along with the vital living force. Prigogine et al [8] explained "Self-Organization in Non-Equilibrium Systems".

Consciousness in living organisms is a process which involves the quantum mechanical activities of these TCP and TRP, the ultimate constituents of any matter as well as any mind in the inherent presence of thought force $\left(\mathrm{T}_{\mathrm{F}}\right)$ in vitro and the thought force $\left(\mathrm{T}_{\mathrm{F}}\right)$ in vivo as indicated by Pal et al $[1,3]$. And these TCP and TRP govern the activities of neurons (not the other way round). Neurons are simply the equipments used to generate consciousness and awareness. The consciousness itself is functioning as an inter-linking agent between the animate and inanimate through the quantum mechanical activities of these TCP and TRP indicated by [3].

\section{Existence of Universal Consciousness}

Pal et al [3] and Pal [7] showed the existence of universal consciousness and explained that the quantized energy $\left(\varepsilon_{T}\right)$ of TCP is responsible to cause the universal consciousness as well as the cosmic microwave background radiation temperature. The individual consciousness owes its origin to the universal consciousness created by the same $\varepsilon_{T}$.

Pal et al [3] have expressed that according to the modern physicists, the universe is the summation of fields, particles, space-time continuum, dark matter, dark energy, void and all the known and unknown parameters of the universe along with all its inhabitants (with or without consciousness), although the universe is always expanding.

The method of integration indicates that

$$
\int d x=x+c
$$

where $\mathrm{c}=\mathrm{a}$ constant. Is there any mathematical fallacy if we like to use 'universe' in the place of ' $x$ ' here? If we at all theoretically like to apply the same method of integration to the whole universe itself, we will have to arrive at

$$
\int d(\text { universe })=\text { universe }+c
$$

where universe $=$ universe with all its known and unknown parameters as well as its inhabitants (with or without consciousness) and $\mathrm{c}=\mathrm{a}$ constant. The constituents of the universe are fields, particles, space-time continuum, dark matter, dark energy, void, all its inhabitants (with or without consciousness) and all the other unknown parameters of the universe that we have not yet faced. We simply propose to apply the method of integration theoretically over the universe as a whole with all its known and unknown parameters and all the inhabitants (with or without consciousness). If we at all theoretically like to do so, we will mathematically arrive at a constant.

What is this constant here? It is our opinion that this constant is the universal consciousness that exists 
throughout the universe in the form of universe wide web (uww) covering fields, particles, space-time continuum, dark matter, dark energy, void and all its known and unknown parameters along with all its inhabitants (with or without consciousness). This universal consciousness is to be taken into account, but usually ignored.

Many physicists agree with the idea that consciousness is non-local, fundamental in the universe and consciousness is very much a part of the universe, like other objects. It is to be noted that $\varepsilon_{T}$, the quantized energy of TCP represents universal consciousness.

Nelson [9], Director of Global Consciousness Project, has observed through the experimentation that coherent consciousness creates order in the world; and subtle interactions link us with each other and the Earth. When human consciousness becomes coherent and synchronized, the behavior of random systems may change. Quantum event based random number generators (RNGs) produce completely unpredictable sequences of zeroes and ones. But when a great event synchronizes the feelings of millions of people, our network of RNGs becomes subtly structured. The probability is less than one in a billion that the effect is due to chance. The evidence suggests an emerging noosphere, or the unifying field of consciousness described by sages in all cultures. This evidence signifies and proves the existence of universal consciousness.

The existence of universal consciousness is explained by Radin [10] through experimentation as it is expressed in his book The Conscious Universe: The Scientific Truth of Psychic Phenomena. Further, Consciousness, not matter, is the ground of all existence, declares University of Oregon physicist Goswami through his published (1993) book, "The Self-Aware Universe: How Consciousness Creates the Material World".

As per Penrose [11], consciousness is a part of the universe. Van De Bogart [12] explained, "Since consciousness is a part of the universe it then follows that all consciousness, and the universe, are of the same matrix of energy fields".

\section{What is the Exact Definition of Mind? What is Mind?}

We observe a great controversy concerning the exact definition of mind. There are two apparently opposite views: one is the substantial view and the other is the functional view.

In the substantial view, the mind is a type of substance. Mind is a finer matter having an autonomous existence. Mind is a single entity, perhaps having its base in the brain but distinct from it. In its most extreme form as in the Indian Upanishads and Vedanta, the mind is not only a finer matter but also it is an entity wholly separate from the body, in fact a manifestation of the soul, which will survive the body's death in the form of the spiritual body or mental body [called Linga Sharira or Sukshma Sharira in Sanskrit] as expressed by Vivekananda [13] who indicated that this mental body bears all the mental impressions. This mental body is also called 'spirit'.

In the functional view, the mind is closely related to the functions of the brain and can have no autonomous existence beyond the brain, nor can they survive its death. In this view, mind is a 'state' created by the activities of the brain with other parts of the nervous system as it is indicated by cognitive neuro-scientists and Artificial Intelligence (AI) scientists. According to them 'minds are simply what brains do'. In this functional view, mind is a subjective manifestation of consciousness: the human brain's ability to be aware of its own existence. The concept of the mind is therefore a means by which the conscious brain understands its own operations.

The modern cognitive neuroscientists generally accept the fact that the "mind" is not an isolated entity and the mind is a state created by the activities of brain with other parts of the nervous system (CNS, PNS along with ANS). Although the mind is generally accepted to be an abstract having no spatial location or public observability, yet it is a type of fine matter according to the ancient Indian Upanishads and Vedanta. The Vedanta indicates that the universe exists along with the universal consciousness. Pal et al $[1,3]$ explained that this universal consciousness is a functional state of the Universal Mind (UM). This UM is constituted by these TCP and TRP which, in turn, are the ultimate constituents of any matter and any mind in the inherent presence of thought force $\left(\mathrm{T}_{\mathrm{F}}\right)$ in vitro and thought force $\left(\mathrm{T}_{\mathrm{F}}\right)$ in vivo. It is to be noted that these TCP and TRP are the ultimate constituents of any matter in the inherent presence of thought force $\left(\mathrm{T}_{\mathrm{F}}\right)$ in vitro. And these TCP and TRP are the ultimate constituents of any mind in the inherent presence of thought force $\left(\mathrm{T}_{\mathrm{F}}\right)$ in vivo. Pal et al [1, $3]$ explained that any matter as well as any individual mind is constituted by these TCP and TRP in the inherent presence of Thought force $\left(\mathrm{T}_{\mathrm{F}}\right)$ in vitro and Thought force $\left(\mathrm{T}_{\mathrm{F}}\right)$ in vivo.

Modern Scientists are not yet able to understand how the brain works to make the mind. They know that brain has got neurons that communicate across synapses by releasing a neurotransmitter, and that generates electrical impulses, and the receiving neuron then talks to its neighbor neurons the same way. If the mind depends on the brain, then all aspects of the mind are going to depend on these simple electrical, chemical processes. According to this concept, the existence of the UM requires the existence of the universal brain to form the UM. The concept of universal brain is not logically acceptable. Thus the concept that the mind depends on the brain becomes questionable if the existence of the UM is valid.

\subsection{It appears that scientists would have to decide in a} purpose to conclude clearly whether mind is a 'state' (created by the activities of the brain with other parts of the nervous system as it is indicated by the functional view of mind) or 'a finer matter' (as it is indicated by the Indian Upanishads and Vedanta). 


\section{How the Mental Impression can be Made Responsible for the Doctrine of Reincarnation through the Activities of TCP and TRP Leading to the Characteristic Hereditary Transmissions}

Pal et al [3] expressed that TCP and TRP are the ultimate constituents of any matter as well as any mind in the inherent presence of thought force $\left(\mathrm{T}_{\mathrm{F}}\right)$ in vitro and thought force $\left(\mathrm{T}_{\mathrm{F}}\right)$ in vivo. It is to be noted that these TCP and TRP are the ultimate constituents of any matter in the inherent presence of thought force $\left(\mathrm{T}_{\mathrm{F}}\right)$ in vitro. And these TCP and TRP are the ultimate constituents of any mind in the inherent presence of thought force $\left(\mathrm{T}_{\mathrm{F}}\right)$ in vivo.

As per Vivekananda [14], there is 'something' which is outside, which is only the occasion, the suggestion; and upon that 'suggestion' I project the TCP of my mind with the help of consciousness; and it takes the form that I see. And the TCP derived from the object is converted into TRP for forming an impression so that I can retain that image with the help of TRP within my mind for future 'recognition' when I would come across the same 'thing'.

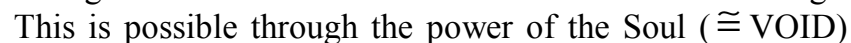
which is the source of infinite energy. The so-called 'mind reading' is possible through the projection of TCP (in the presence of TRP) in the inherent presence of thought force $\left(\mathrm{T}_{\mathrm{F}}\right)$ in vitro and thought force $\left(\mathrm{T}_{\mathrm{F}}\right)$ in vivo as indicated by Pal et al [3].

The foremost role of the brain is to receive external information through various channels, to differentiate them bit by bit and spread them throughout the brain in waves of electrical pulsation for symbolization. The symbolized information is maintained for future recognition of any object through the integration into consciousness. It is here that judgments play a role, comparing present information with past experience, data of which is kept coded in the memory shelves.

S. Vivekananda [15] expressed: Let us consider the process by means of which the knowledge is acquired. Suppose we see a dog. How do we know that it is a dog? We refer it to our mind, and in our mind there are groups of all our past experiences, arranged and pigeon-holed [with the help of TRP just like 'memories' conserved through the microchips in the CPU of a computer system]. As soon as a new impression comes, we take it up and refer it to some of the old pigeon-holes, and as soon as we find group of the same impressions already existing, we place it in that group and we are satisfied......this state is called "knowledge". We know that it is a dog because it coincides with impressions already there. When we do not find the cognates of this new experience inside, we become dissatisfied....this state of mind is called "ignorance". We see the power of acquiring knowledge varies in each individual and this shows that each one of us has come with his own fund of knowledge. Knowledge can only be got by the way of experience... there is no other way to know. If we have not experienced it in this life, we must have experienced it in other lives. [Thus TRP may ultimately have a direct effect on the functioning of "gray matter" of the human brain].

6.1. Fritjof Capra [16] expressed, "Both kinds of interconnectedness---that between mind and body and that between organism and environment---would have to be interpreted in terms of tentative notions of energy patterns. The Indian concept of 'Prâna' and the Chinese concept of ch' $i$ are to be taken into account as examples of traditional terms referring to these 'subtle energies', or 'life energies'. In these traditional disciplines illness is seen as resulting from changes in the patterns of energy and therapeutic techniques have been developed to influence the body's energy system".

According to the ancient Indian Vedanta, this Universe is composed of 'Âkâsha' and 'Prâna' as indicated by Vivekananda [17]. 'Âkâsha' is the origin of all the observable matter. And 'Prâna' is the origin of all the natural fields along with vibrations (Thought). This natural field includes the 'vital living force' which, in turn, controls all the psychological as well as the physiological functions of all living beings of the universe. It is to be noted that this Prâna $\cong$ the Indian concept of 'life energies'. And this vital living force as well as the thought force is usually ignored.

It is to be noted that Prâna ( $\cong$ 'vital living force') $\cong$ thought force $\left(\mathrm{T}_{\mathrm{F}}\right)$ in vitro + thought force $\left(\mathrm{T}_{\mathrm{F}}\right)$ in vivo $+\mathrm{T}_{\mathrm{F}}$ (micro) $+\mathrm{T}_{\mathrm{F}}$ (macro).

Pal [5] explained vividly the existence of thought force $\left(\mathrm{T}_{\mathrm{F}}\right)$ in vitro and thought force $\left(\mathrm{T}_{\mathrm{F}}\right)$ in vivo and other aspects of Thought force $\left(\mathrm{T}_{\mathrm{F}}\right)$ like $\mathrm{T}_{\mathrm{F}}$ (micro) and $\mathrm{T}_{\mathrm{F}}$ (macro) along with all their characteristics.

Swami Vivekananda [17] expressed: Is the physical body of a living being cause of manifestation of the Soul ( $\cong$ Void) or 'vital living force' (called Prâna, the Indian concept of 'life energies')? What makes this body? What force causes the atoms to combine in a specific sequence and takes up specific atoms from the mass of matter around us in order to provide different shapes of different species of specific bodies of living beings? It is logical to say that the force which makes up the matter and forms the body, is the same force which is responsible for causing and maintaining the psychological as well physiological functions of the living organisms. This specific force is called "Prâna", the Indian concept of 'life energies'. The sum-total of the energy displayed in the universe is called Prâna indicated by Vivekananda [17]. This Prâna is thought to be the 'universal power'. The Prâna is the gross origin of all the fundamental fields including the 'vital living force' which controls all the psychological as well as the physiological functions of all living beings of the universe. TCP is the force-carrying particle of the original thought force $\left(\mathrm{T}_{\mathrm{F}}\right)$ which is the origin of all the existing natural fields. Thus, this "Prâna" is more or less equivalent to the original 
thought force $\left(\mathrm{T}_{\mathrm{F}}\right)$ which is carried by TCP in the inherent presence of TRP. Does this Prâna generate consciousness? Or does the consciousness create Prâna? Are they interdependent or intra-dependent? It is apparent that the consciousness being a typical form of energy can initiate the function of Prâna. Life may be defined as a state of functional manifestation of consciousness that, in turn, is the quantized energy $\left(\boldsymbol{\varepsilon}_{T}\right)$ of the TCP. This $\boldsymbol{\varepsilon}_{T}$ represents consciousness.

As a separate entity, the Prâna as well as consciousness appears to be independent or they may appear to be interdependent; but, after the initiation of the function of Prâna in a living organism, they are intra-dependent. Thus, when this specific Prâna ( $\cong$ 'vital living force') is eliminated from the living organism, then that living being is said to die.

Pal [5] expressed that the thought force $\left(\mathrm{T}_{\mathrm{F}}\right)$ being the primordial quantum field functions as the original single primary unified field that is not only the origin of all the four fundamental fields along with both the $\mathrm{T}_{\mathrm{F}}$ (micro) and $\mathrm{T}_{\mathrm{F}}$ (macro) but also the origin of thought force $\left(\mathrm{T}_{\mathrm{F}}\right)$ in vivo.

Thus, the original thought force $\left(\mathrm{T}_{\mathrm{F}}\right)$ which is the primordial quantum field and which is an expression of the universal consciousness represents 'Prâna' that, in turn, is the origin of all the natural fields (including the vital living force) and TRP represents 'Âkâsha'. This 'Prâna' is manifested as nerve-current as well as the biological 'thought force' also. And all the psychological and physiological activities are controlled and maintained by this same 'Prâna' itself.

6.2. As per Vivekananda [18], When the physical body dissolves, the 'vital living forces' of the man go back to his mind, and the mind becomes dissolved, as it were, into the Prâna (= universal power); and the Prâna enters into the soul of man, and thus the soul of man comes out, clothed, as it were, with what is called fine body, the mental body or "spiritual body" (called Linga/Sukshma Sharira in Sanskrit). The 'mental impressions' of the man are present in his mental body with the help of TCP and TRP.

As per Vivekananda [18], each work we do, each thought we think, produces an impression (called Samaskaras in Sanskrit), upon the mind and the sum total of these impressions becomes tremendous force (called the character) which gives a man the next direction after death. A man dies; the body falls away and goes back to the elements; but the mental impressions remain, adhering to the mind which, being made up of TCP and TRP, does not dissolve immediately but persists in this world. Vivekananda [18] illustrated the affair by taking the example of whirlwind which can form a body of dust drawing in bits of paper, straw etc. at one place, only to drop them and go on to another place. Force cannot travel without matter. So when the body falls down, the mind-stuff bearing these mental impressions remains with the help of the related 'binding force' derived from the Prâna through the activity of TCP and TRP. The strength of this 'binding force' is dependent on the degree of desire of an individual. This
Prâna which causes it to move on to another point, raises up another whirl from fresh materials, and begins another motion; and thus it travels from place to place until the 'binding force' is all spent. And then it falls down, ended. So when the mind will be broken entirely into its constituents so as to release the original TCP and TRP, without leaving any mental impression, we shall be entirely free. And until that time we are in bondage; until then the soul (Âtman) is covered by the whirl of mind, and imagines it is being taken from place to place. When the whirl falls down, the soul finds that it is all-pervading. It can go anywhere it likes, is entirely free, and is able to manufacture a number of minds and bodies it likes; but until then it can go with the whirl. This freedom is thought to be the goal towards which we all are moving.

6.3. What is called spirit ( $\cong$ ghost) is not exactly equivalent to soul (Atman). This spirit is more or less equal to the mental body as indicated by Vivekananda [13]

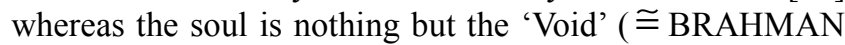
of Vedanta). When the physical body is abolished, the eternal Void ( $\cong$ BRAHMAN) is not at all abolished simultaneously and will never be abolished along with the dissolution of the physical body. On the contrary, the eternal 'Void' being covered by the individual mind to serve the role of individual soul comes out with the specific mental impression to form the spirit ( $\cong$ mental body). This spirit ( $\cong$ mental body) with its 'mental impression' will have to adopt series of proper physical bodies to satisfy the previously unfulfilled desires as per the 'law of KARMA'. And this process continues until it is united with the original eternal Void (called the BRAHMAN) which is the origin of anything and everything of this universe. The existence of spirit ( $\cong$ mental body) can be explained only if the existence of the doctrine of "reincarnation" indicated by Vivekananda [19] is accepted through the well known "law of Karma".

If the existence of the spirit ( $\cong$ mental body) along with the "reincarnation" is accepted, then it will be easier to explain not only the power of selection of atoms to form the specific living body but also specific characteristic hereditary transmission indicated by Vivekananda [20]. Modern scientists believe in hereditary transmission and although, sometimes presume that the infinite amount of impressions from all the time are entering into this bioplasmic cell of the zygote, but they are not yet able to prove how and where these impressions live in the cell. The job will not really be over by expressing the idea that the mental impressions are sleeping in the sequence of the four bases (Adenine, Thymine, Guanine, Cytosine) of the double helical structure of the DNA of the physical cell.

What force is controlling the arrangement of the sequence (of four bases in the DNA) that is responsible for hereditary transmission? The exact vehicle through which these hereditary transmissions are truly being conveyed has not yet been thoroughly established. In this context we like to emphasize that there is a high probability that the 
arrangement of "base-sequence" in DNA is absolutely governed by the activity of TCP and TRP of the finer mental body. As TCP and TRP obey quantum theory, so this view agrees well with the idea of Schrodinger [21] who, many decades ago, had written: "The mechanism of heredity is closely related to, nay founded on , the very basis of quantum theory ". It is probable that the instructions and information contained in DNA /RNA are coming from the UM through the TCP and TRP.

It has been clearly established that DNA (Deoxyribonucleic acid), is the carrier of genetic information in the living cells and the DNA content of the somatic cells of a given species is constant and twice that of the sperm cells and ova. Although it is assumed that DNA carries heritable information in the sequence of its four bases, yet the exact and appropriate explanations regarding the hereditary transmission is yet to be properly established due to the observation of the fact that the progenies of the same parent can function quite differently so as to establish themselves as per their mental impressions e.g. Swami Vivekananda (world famous unparalleled Vedantist and spiritualist), Rabindranath Tagore (India : Nobel laureate in literature in 1913). Faraday (world famous technologist and scientist), Charlie Chaplin (world famous film star and director) and so and so forth. On the other hand, it is also not usually observed through the so-called hereditary transmission that a world famous scientist has given birth to the progeny of the same remarkable scientific level.

6.4. It is to be noted that the term "hereditary transmission" is valid so far as furnishing the specific atoms of the desired materials to the soul is concerned indicated by Swami Vivekananda [19, 20]. All involuntary actions in the living beings, which have become instinctive are the result of past experiences. Mental experiences belong to the finer mental body that is operated by its own soul $(\cong$ Void $)$. The mental impressions caused by the mental experiences are transmitted only through the activity of its TCP and TRP of the mind of mental body in order to produce a specific sequence of the four bases of DNA but not through the physical external body or not through the bio-plasmic cell of the zygote as it is supposed by the modern molecular biologists. Because the father's total characteristics or impressions does not come to the child in toto. The same parents may have number of children; then, from this theory of hereditary transmission where the impression and the impressed (that is to say, material) are one, it clearly follows that by the birth of every child the parents must loose a part of their own impressions. If the parents should transmit the whole of their impressions, then after the birth of the first child, their mind will be a vacuum. It is thus obvious that the impression is in the mind and the mind comes to take its birth and re-birth and uses the material, which is most proper for it through the activity of its TCP and TRP. The soul (Jivâtman) migrates and manufactures body after body and each thought, we think and each deed we do, is stored in it in fine forms, ready to spring up again and take a new shape to satisfy the previously unfulfilled desires as per the "law of Karma".

\section{Discussion and Conclusion}

Modern scientists are not yet able to uncover the veil of mysterious origin of "life'. How the "vital life principle" gets its entry? Or how the 'life' begins its functions to catalyze its own function within the zygote formed by the union of two gametes? This zygote ultimately gives rise to a progeny of that family of living being.

Is there any natural reason why all the sperm cells are not united at a time with all the ova to form many zygotes during the fertilization through sexual reproduction? Out of billions of spermatozoa only one specific spermatozoon is able to unite with only one ovum in the fertilization through sexual reproduction in humans. Although the unions of the two or more sperm cells with two or more ova at a time are rare occasion in human beings, yet they are the usual phenomena in other mammals. Is this specification due to the fact that the mind of the mental body would select and adopt a specific zygote to initiate the function of Prâna so as to generate the "life function" of that specific living being in a purpose to satisfy the previously unfulfilled desires as per the "law of Karma"? Do the TCP and TRP of the mind of mental body play fundamental role to select even the specific type of zygote? Is the formation or selection of the zygote itself totally governed by the activity of TCP and TRP of the mind of mental body? Answers to all these questions are necessary to realize the cause of heredity as well as the generation and maintenance of "life function" of the progenies produced through the doctrine of "reincarnation". At the same time question arises: what is then the so called "mental impression" and its related roles involving the "reincarnations" all about when there was no "life" at all after the beginning of the universe? There is no appropriate answer except to mention (as it is expressed in some religions) that it is purely due to the "wish" or "fate" (or "LILA") of the Absolute (三Void) to express itself through the UM which, in turn, gets opportunity to manifest its own inherent characteristics through the generations of each and all individual minds in a purpose to realize the "reality" of the universe itself.

Even the creation of a new biological species through the mutation in the "gene" of any living being is possible by the activity of its mind. As per the constant desire of any living being which faces difficulty to survive, TCP and TRP of its mind can cause mutation in the gene in order to create a new class of progeny, which would be able to adjust with the prevailing environment for its survival. The existence of the postulated TCP and TRP and their fundamental roles can explain Darwin's idea of spontaneous fluctuations in biological species, which then through the selection from the medium lead to irreversible biological evolution, to self-organization.

The biological evolution either through the natural selection or through the 'gene mutation' is caused by the quantum mechanical activities of these TCP and TRP 
governed by the quantum theory as per the directive of the UM. The evolution of life and consciousness may be caused by the quantum mechanical activities of these TCP and TRP through the generation of RNA or DNA as per the directive of the UM.

The evolution of life having mind and consciousness is, in our view, possible purely due to the ultimate fate of the

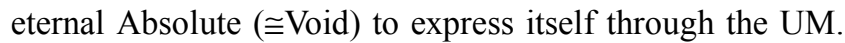
Without the inherent existence of the universal consciousness, the inanimate matter itself can not generate consciousness which is an inter-linking agent between the inanimate and animate. And further universal consciousness is a functional state of the UM which is constituted by these TCP and TRP. These TCP and TRP, in turn, are the ultimate constituents of any matter and any mind in the inherent presence of thought force $\left(\mathrm{T}_{\mathrm{F}}\right)$ in vitro and the thought force $\left(\mathrm{T}_{\mathrm{F}}\right)$ in vivo as indicated by Pal et al [3]. This UM along with the universal consciousness is thus responsible for the manifestation of this Universe with all of its inhabitants. As this UM manifests its own inherent characteristics through the generations of each and all individual minds in a purpose to realize the "reality" of the universe itself, so the biogenesis may be thought to be predetermined. A living organism is thus a complex information processing system and the information is coming from the UM through TCP and TRP. Thus the

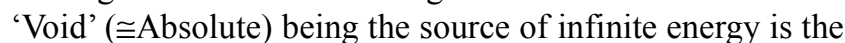
origin of anything and everything in this universe through the presence of universal consciousness. Therefore, the natural physical laws governed by the eternal 'Void' (Absolute) cause the evolution of life with consciousness through the generation of DNA and RNA by the quantum mechanical activities of these TCP and TRP which are conceived to be not only the constituents of the UM but also the ultimate constituents of any matter as well as any mind.

\subsection{How to Explain the Generation of Living being Produced by Cloning?}

In this case the live cells are used and caused to take part in cloning. The presence of 'life' indicates the presence of mind, a constituent of the UM. The "mind" is constituted or operated by these TCP and TRP. Pal et al $[1,3]$ showed that the quantized energy $\left(\varepsilon_{T}\right)$ of TCP is responsible to cause the universal consciousness as well as the cosmic microwave background radiation temperature. The individual consciousness owes its origin to the universal consciousness created by the same $\varepsilon_{T}$. Ultimately this $\varepsilon_{T}$ represents universal consciousness. This consciousness is responsible for maintaining the state of "flux" called "life". Thus the organism produced by cloning must have its own typical individual mind through which the soul exerts its own functions. What are the characteristics of this specific individual mind pertaining to the mental impressions? Is it a fresh pure mind or a specific individual mind having the resultant combinations of mental impressions belonging to cells of its parent or parents? Is it a fact that the live cells should have some sorts of mind? It is obvious that the normal activity of TCP and TRP must be present to maintain the living nature of the cell and these TCP and TRP are the constituents of the mind. Thus there is the presence of the function of mind in any living cell through the activity of TCP and TRP. It is illogical to assume that cloned organisms are in a state of "superconsciousness", having the characteristics of the 'void'.....it is to be understood that super-conscious state is as good as void. It is to be noted that pure mind is the mind without any mental impression within it; thus the pure mind means the original TCP and TRP with which the UM is constituted. This UM, in turn, is evolved from the eternal void.

Thus, it is to be understood that, as the cloned organism cannot have the fresh original pure mind, so it must have a mind having the resultant combinations of mental impressions derived from the parent cells.

\section{References}

[1] D. Pal and A.U. De, Physics of consciousness and its model may provide guidelines to solve Many scientific problems. Neuroquantology 1: 17-28(2004)

[2] D. Pal and A.U. De, Consciousness model: Significance of thought-carrying particles and thought-retaining particles in quantum measurement as well as cognitive problem. Neuroquantology 2: 115-116 (2005)

[3] D. Pal and A.U. De, The cosmic microwave background radiation temperature signifying the existence of the thought-carrying particle, thought retaining particle and thought force. NeuroQuantology 10: Issue3; 428-442 (September 2012)

[4] M. Bhaumik, Code Name GOD. (Penguin Books India Pvt. Ltd., 11 Community Centre, Panchsheel Park, New Delhi 110017 , India) pp. 132-133; 161-162; 167; 171; 177; 183 and 184. 185-186; 89-190; 198 (2006)

[5] Dhananjay Pal, Existence of Thought Force and Its Characteristics, American Journal of Physical Chemistry. Vol. 2, No. 5, 2013, pp. 94-104. doi: 10.11648/j.ajpc.20130205.13

[6] V. F. Weisskopf, The Origin of the Universe, The World of Physics, (Simon and Schuster, 1230 Avenue of Americas, New York 10020) 3, pp. 10 and 314 (1987)

[7] D. Pal, Existence of universal consciousness and its characteristics. Accepted for publication In 2014 International Conference on Advanced Education and Management (ICAEM2014) Beijing, China (2013)

[8] I. Prigogine and G. Nicolis, Self-Organization in NonEquilibrium Systems. (Wiley 1977) ISBN 0471024015.

[9] R. Nelson, Director, Global Consciousness Project, Princeton, New Jersey. (2009) rdnelson@princeton.edu

[10] D. Radin, The Conscious Universe: The Scientific Truth of Psychic Phenomena. (Harper Edge) (1997) ISBN 0-06251502-0. 
[11] R. Penrose, Shadows of the Mind: A Search for the Missing Science of Consciousness. (Oxford University Press) (1994)

[12] W. Van De Bogart, Earth portals: Exploring New Metaphors of Consciousness 1993 willard@earthportals.com

[13] S. Vivekananda, Soul, Nature and God (Linga Sharira or Sukshma Sharira). The complete works of Swami Vivekananda. (Advaita Ashrama, India) 2: pp-424 and 438; ibid. The real and apparent man (Samaskaras) 2: pp-268-269 (1989)

[14] S. Vivekananda, Cosmology (What is external nobody knows). The complete works of Swami Vivekananda. (Advaita Ashrama, India) 2: pp-441 (1989)

[15] S. Vivekananda, Cosmology (How do we know that it is a dog?). The complete works of Swami Vivekananda. (Advaita Ashrama, India) 2: pp-219 (1989)

[16] Fritjof. Capra. Uncommon Wisdom. Flamingo, An Imprint of Harper-Collins Publishers. p-159 and 216-217. (1989)
[17] Vivekananda. RAJA-YOGA, The complete works of Swami Vivekananda, Advaita Ashrama. 1: p-223; ibid.; PRANA, 1: p-147- 173. ibid.; The Cosmos (the Microcosm); 2: p-212225 (1989)

[18] Vivekananda. The Real \& The Apparent Man, The complete works of Swami Vivekananda, Advaita Ashrama. 2: p-268269; ibid.; The Atman: Its Bondage \& Freedom, 2: p-255256 (1989)

[19] Vivekananda. The Cosmos (Reincarnation), The complete works of Swami Vivekananda, Advaita Ashrama. 2: p-217225 (1989)

[20] Vivekananda. The Cosmos (Heredity Transmission), The complete works of Swami Vivekananda, Advaita Ashrama. 2: p-219-225 (1989)

[21] E. Schrödinger. What is life? with Mind and Matter. Published by Cambridge University Press. 2000. 